\title{
Uma Abordagem Para Avaliação De Jogos Educativos: Ênfase No Ensino FUNDAMENTAL
}

\author{
Maxwell de Oliveira Medeiros - Universidade Cruzeiro do Sul - \\ maxdeoliveira@gmail.com \\ Prof. Dr. Juliano Schimiguel - Universidade Cruzeiro do Sul - \\ juliano.schimiguel@cruzeirodosul.edu.br
}

\begin{abstract}
Resumo
Este artigo apresenta uma análise a respeito da utilização de jogos eletrônicos na educação como uma forma de auxiliar o processo de aprendizado, tornando-o mais interativo, imersivo, dinâmico e motivador. $\mathrm{O}$ artigo se baseia principalmente em uma revisão de literatura sobre os benefícios dos jogos educacionais e também apresenta uma breve análise da viabilidade e de alguns pontos-chave a se observar na aplicação de jogos eletrônicos nas escolas. Por fim, sugerimos uma abordagem para avaliação de jogos eletrônicos educacionais para auxiliar os professores a escolherem os jogos que melhor se adaptam aos seus planos de ensino.
\end{abstract}

Palavras-chave: jogos eletrônicos, jogos educacionais, ensino fundamental, avaliação de jogos

\section{An ApProach For AsSesSment Of EduCATIONAL GAMES: EMPHASIS ON BASIC EDUCATION}

\begin{abstract}
This article presents an analysis about the use of video games in education as a way to assist the learning process, making it more interactive, immersive, dynamic and motivating. The article is based primarily on a review of literature on the benefits of educational games and also presents a brief analysis of the feasibility and some key points to be noted in the application of computer games in schools. Finally, we suggest an approach for evaluation of educational electronic games to help teachers choose the games that best suit their teaching plans.
\end{abstract}

Keywords: electronic games, educational games, elementary education, games evaluation

\section{Introdução}

Segundo a pesquisa Motivos da Evasão Escolar, realizada em 2009 pela Fundação Getúlio Vargas - FGV-RJ, 40\% dos jovens de 15 a 17 anos deixam de estudar simplesmente porque acreditam que a escola é desinteressante.

Mesmo com diversos estudos indicando a importância do lúdico no processo de aprendizagem, no processo de tomada de decisões, no desenvolvimento cognitivo e na 
estimulação da criatividade, a utilização de jogos eletrônicos ainda é pouco discutida. Além disso, o próprio conceito de aprender brincando vai se perdendo conforme o aluno avança na escola, a idéia de lúdico é mais priorizada na educação infantil e deixa de ser utilizada na educação fundamental.

Isso pode ser visto até nas Diretrizes Curriculares Nacionais (DCNs), normas obrigatórias para a Educação Básica que orientam o planejamento curricular das escolas e sistemas de ensino, fixadas pelo Conselho Nacional de Educação (CNE).

No artigo 22, que explica os objetivos da educação infantil, o parágrafo segundo mostra a preocupação com o estímulo da curiosidade a partir da brincadeira:

"Art. $22-\S 2^{\circ}$ Para as crianças, independentemente das diferentes condições físicas, sensoriais, intelectuais, lingüísticas, étnico-raciais, socioeconômicas, de origem, de religião, entre outras, as relações sociais e intersubjetivas no espaço escolar requerem a atenção intensiva dos profissionais da educação, durante o tempo de desenvolvimento das atividades que lhes são peculiares, pois este é o momento em que a curiosidade deve ser estimulada, a partir da brincadeira orientada pelos profissionais da educação".

Já na seção do ensino fundamental, que vai dos artigos 23 ao 25 , nada é falado a respeito de se estimular a curiosidade do aluno, cativar o seu interesse e promover o uso da brincadeira e do lúdico como forma de motivação.

É comum o aluno ter dificuldades no aprendizado e falta de interesse pelo conteúdo apresentado em sala de aula. Considerando que a criança de hoje tem acesso à tecnologia desde muito cedo, este estudo propõe a avaliação da utilização de jogos eletrônicos como uma boa alternativa para atrair o interesse do aluno, tornando o conteúdo apresentado mais interessante, interativo, significativo e desafiador, uma forma de unir diversão com aprendizado.

Este artigo está dividido em três partes, primeiramente é apresentada uma revisão da literatura abordando os benefícios da utilização de jogos na educação, uma breve análise da viabilidade de aplicação de jogos eletrônicos em escolas públicas e alguns desafios no desenvolvimento e na aplicação de jogos eletrônicos educacionais. Em seguida apresentamos uma análise de algumas metodologias de avaliação de softwares e jogos eletrônicos, uma proposta de uma abordagem voltada especificamente para avaliação de jogos eletrônicos educacionais e um estudo de caso com o jogo Stop! sendo avaliado pelos critérios propostos. Por último, encontram-se as considerações finais do trabalho apresentando uma síntese do conteúdo exposto.

\section{Referencial Teórico}

Com o aumento exponencial do uso de tecnologia em todas as idades, o acesso a informações se tornou muito fácil, surgiram novas formas de agir e pensar. Um profissional capaz de se reinventar de acordo com as necessidades do momento se tornou mais desejado do que um profissional que sempre age da mesma forma, que nunca está disposto a mudar. Essa nova dinâmica do mercado fez com que o modelo de ensino das escolas fosse questionado, pois aquele padrão onde o professor simplesmente transmite as informações e os alunos as decoram ficou defasado e desmotivador. Agora é necessário que os alunos aprendam a aprender, que sejam capazes de construir novos conhecimentos a partir das informações disponíveis.

Segundo Antunes (1998), o papel da escola renova-se com estudos e descobertas sobre o comportamento cerebral e, nesse contexto, a nova escola é a que assume o papel de "central estimuladora da inteligência". Se a criança já não precisa ir à escola para aprender, ela necessita da escolaridade para "aprender a aprender", desenvolver suas 
habilidades e estimular suas inteligências. $\mathrm{O}$ professor não perde espaço nesse novo conceito de aula, ao contrário, transforma a sua profissão na mais importante de todas por ser um estimulador da inteligência e agente orientador da felicidade. Perderão espaço a escola e os professores que agem como simples agentes transmissores de informação.

O pesquisador Delors (1999) afirma que o acesso puramente quantitativo a um volume cada vez maior de material de estudo nas escolas é um modelo inadequado e defende que é necessário saber se adaptar a um mundo de mudanças. $\mathrm{O}$ autor ressalta a importância de levar-se em consideração a educação não somente como uma etapa na vida do indivíduo, mas sim como um processo desenvolvido durante toda a sua existência.

Jogos com finalidades educacionais são utilizados na busca por formas mais dinâmicas e interessantes para motivar o aluno a construir seus conhecimentos. $\mathrm{O}$ uso de jogos na educação é encorajado por autores como Dohme (2008), que afirma que, além de serem fontes de diversão, os jogos podem ser utilizados para vários fins educativos e como instrumentos de desenvolvimento de crianças e jovens. A autora explica que, para as crianças, o jogo constitui um fim, onde o objetivo principal é a diversão. Já para os educadores, o jogo é um meio, um veículo que permite transmitir uma mensagem educativa de forma atraente e prazerosa, cabe ao professor escolher o jogo que melhor se aplica ao conteúdo que deseja ensinar.

Esclarecendo melhor o prazer das crianças ao aprender de forma lúdica, Moran (2002) descreve que a mídia, para os alunos, significa descanso e não "aula", o que modifica a sua postura e as expectativas em relação ao seu uso, e essa é uma boa oportunidade para aproveitar essa expectativa positiva para atrair o aluno para os assuntos do planejamento pedagógico.

Para Santos e Vale (2006), quando o aluno participa de um jogo, ele sai da passividade sendo colocado em uma situação-desafio que dispõe de diversas ferramentas com as quais ele deve resolver o problema proposto. Há a necessidade de formar novas associações cognitivas a fim de se chegar a uma solução, e ele passa, então, a construir seu conhecimento.

Seguindo o mesmo raciocínio, Dohme (2008) afirma que o jogo é um grande campo onde as crianças vivenciam, de forma livre e autônoma, o relacionamento social. Através do jogo, as crianças podem interagir entre si, vivenciando situações, indagando, formulando estratégias, verificando seus acertos e erros e, por ser um ambiente controlado, elas podem reformular seus planejamentos e tentar novamente.

Com o desenvolvimento tecnológico, surgiu uma nova modalidade de jogos, os eletrônicos, mas a utilização desse tipo de jogo na área da educação ainda sofre preconceitos, pois muitas vezes ele é visto como uma perda de tempo, algo que os jovens acabam se viciando e que não os ensina nada.

Johnson (2006), analista de tecnologia digital, sugere que o jogo eletrônico é uma das mídias mais interativas que existem, onde o jogador é forçado a tomar decisões e para isso precisa sistematizar e avaliar todas as informações disponíveis e também definir estratégias para alcançar seus objetivos, de longo ou de curto prazo. Para o autor, o que traz benefício não é a decisão em si, mas o processo de reunir e analisar informações. Com isso, o jogador acaba desenvolvendo a capacidade cognitiva e exercitando as estruturas cerebrais responsáveis pelas escolhas e iniciativas.

Como as crianças têm acesso a jogos eletrônicos em suas casas cada vez mais cedo, ao chegar na escola, ela sofre um choque de comportamento por ter que ficar sentada, prestando atenção a uma única pessoa falando e escrevendo numa lousa. 
Moran (2002) explica que a criança, antes mesmo de começar a ir à escola, já passou por processos de educação importantes no ambiente familiar e pela mídia eletrônica, principalmente pela televisão. $\mathrm{O}$ autor afirma que, através da mídia, a criança aprende a conhecer os outros, o mundo e a si mesma, aprende também a informar-se, a sentir, a fantasiar e a relaxar; vendo, ouvindo ou "tocando" as pessoas na tela, que lhe mostram como viver, ser feliz e infeliz, amar e odiar.

Complementando, Moran (2002) afirma que a mídia eletrônica é prazerosa e sedutora, mostra o mundo de maneira fácil, agradável e compacta, e isso proporciona que ela eduque enquanto estamos entretidos.

Tendo em vista a mudança brusca de ambiente que a criança sofre, Schneider (APUD Santos e Vale, 2006) alerta sobre a necessidade de romper com o atual paradigma da educação, levando-se em consideração:

- A importância da interatividade para manter a atenção do estudante;

- O desenvolvimento de um ambiente sem riscos no qual o aluno possa testar os seus conhecimentos;

- A individualidade de cada aprendiz, uma vez que cada um pode aprender de forma diferenciada, assimilando conhecimentos e experiências em seu próprio ritmo.

Mesmo que vários autores atestem a eficiência de jogos eletrônicos na promoção de um ensino mais motivador, de nada adianta se as escolas não tiverem a capacidade tecnológica para proporcionar a sua utilização nas aulas. No próximo capítulo, avaliaremos a viabilidade da aplicação de jogos eletrônicos nas escolas públicas do Brasil.

\subsection{Tecnologia Necessária Para o Uso de Jogos Eletrônicos Na Escola}

A cultura de jogos eletrônicos no Brasil já está muito bem difundida, uma prova disso está numa pesquisa de mercado feita pela empresa Newzoo, que lançou em $2011 \mathrm{um}$ relatório mostrando que o Brasil se transformou em um mercado chave do setor de jogos, comparável em tamanho aos maiores países europeus. O relatório oferece informações detalhadas sobre o comportamento, as preferências e os gastos do mercado de jogos da população on-line ativa do Brasil que conta com 46 milhões de pessoas entre 10 e 65 anos de idade. Os resultados são impressionantes, 76\% dessas pessoas jogam algum jogo, isso equivale a 35 milhões de jogadores brasileiros jogando uma média de 64 milhões de horas por semana ao todo. A previsão é que, no ano de 2011, sejam gastos US\$ 2 bilhões em jogos, sendo a maioria desses gastos em jogos on-line e para celular.

Nas escolas públicas, a instalação de laboratórios vem sendo feita pelo Governo através do Ministério da Educação (MEC), que criou o Programa Nacional de Tecnologia Educacional (ProInfo), que é um programa educacional criado pela Portaria $\mathrm{n}^{\mathrm{o}}$ 522/MEC, de 9 de abril de 1997, para promover o uso pedagógico de Tecnologias de Informática e Comunicações (TICs) na rede pública de ensino fundamental e médio e, com isso, cada vez mais crianças e adolescentes poderão usufruir de uma educação mais interativa por meio da informática.

Outra medida adotada pelo Governo Federal é o Programa Banda Larga nas Escolas (PBLE), lançado em 2008, que tem como objetivo conectar todas as escolas públicas urbanas à Internet, rede mundial de computadores, por meio de tecnologias que propiciem qualidade, velocidade e serviços para incrementar o ensino público no País e que, no fim de 2010, já tinha contemplado cerca de $91 \%$ das escolas públicas urbanas do país. 
As escolas públicas contempladas por esses dois programas criados pelo Governo, já devem possuir a tecnologia necessária para utilizar jogos eletrônicos como ferramentas auxiliares na educação.

\subsection{Desafios Na Aplicação De Jogos Eletrônicos Educacionais}

Tavares (20--), mesmo afirmando que os jogos têm poder educacional e são fortes aliados na construção de conhecimentos, atesta que é um desafio incluir em salas de aulas jogos que os jovens gostem e que tenham alguma aplicação educacional, para ele:

"Os jogos educativos mais comuns são chatos e tendem a se tornar uma obrigação para crianças e adolescentes. Não adianta usarmos personagens e histórias que não encantem os alunos. Mesmo porque, ao sair da aula, eles voltam à rotina, com games considerados agressivos pela maioria dos educadores".

Tavares (20--) explica ainda que há dois pontos fundamentais no desenvolvimento de jogos eletrônicos educativos: a interface e a didática. A comunicação homem-máquina deve ser amigável, intuitiva e precisa. Para isso, o designer precisa encontrar soluções que facilitem a ação do usuário. "Games que requerem a leitura de grandes manuais, certamente, têm problemas de design". Outra questão primordial é a didática, se os jogos forem apresentados como educacionais o usuário perderá o interesse. "Um bom jogo não declara sua proposta educacional de imediato. O ideal é que o aluno tenha vontade de jogar e, sem perceber, aprenda mais sobre a cultura européia tentando pegar a ladra Carmen San Diego", sugere.

Antunes (2002) cita dois aspectos cruciais no emprego dos jogos como instrumentos de uma aprendizagem significativa. Em primeiro lugar, o jogo ocasional, distante de uma cuidadosa e planejada programação, é tão ineficaz quanto um único momento de exercício aeróbico para quem pretende ganhar maior mobilidade física e, em segundo lugar, uma grande quantidade de jogos somente tem validade efetiva quando rigorosamente selecionados e subordinados à aprendizagem que se tem em mente como meta. O autor alerta para que os jogos nunca sejam usados sem um planejamento cuidadoso, com etapas nítidas que acompanhem o progresso do aluno e que a qualidade dos jogos escolhidos é muito mais eficiente do que a quantidade destes.

Seguindo a mesma linha de raciocínio estão Pietruchinski et al (2001), que atestam que os jogos no processo de ensino e aprendizagem são ferramentas capazes de auxiliar no processo educativo, desde que sejam planejados e trabalhados de uma forma crítica, que possibilite a aprendizagem de uma maneira significativa ao aprendiz.

Fontoura (2012) explica que transformar um conteúdo qualquer para um formato de jogo, não o torna interessante magicamente, existem inúmeros jogos educativos muito ruins que não motivam em nada o aluno. Para o autor, é fundamental que o jogo educacional não tenha a pretensão de eliminar o esforço da aprendizagem, a primeira preocupação ao se desenvolver um jogo educacional, então, deve ser o ensino significativo, ou seja, oferecer algo a mais na exposição do conteúdo, permitir uma maneira diferente de encarar o conhecimento. Só assim o aluno se sentirá desafiado ou motivado a colocar em prática o conteúdo aprendido.

Considerando o que foi exposto até aqui, fica claro que um grande desafio de incluir jogos eletrônicos nas escolas é o desenvolvimento de jogos que consigam equilibrar o lúdico e o ensino significativo, que seja motivante e cativante, mas ao mesmo tempo exija esforço mental da parte do aluno para que se produza o efeito desejado, uma educação de qualidade.

Para auxiliar o professor na tarefa de escolher um jogo que traga benefícios aos alunos, abordaremos no próximo capítulo o uso de uma abordagem para avaliação de jogos eletrônicos educacionais. 


\section{Metodologias De Avaliação}

Segundo a norma ISO/IEC 9126 (APUD Gladcheff et al, 2011), Qualidade de Software é definida como "a totalidade das características de um produto de software que lhe confere a capacidade de satisfazer necessidades explícitas e implícitas". A norma ISO/IEC 9126 (NBR 13596) propõe um conjunto de características que devem ser verificadas em um software para que ele tenha sua qualidade assegurada. Esta norma abrange seis grandes grupos de características, mostrados na Figura 1.

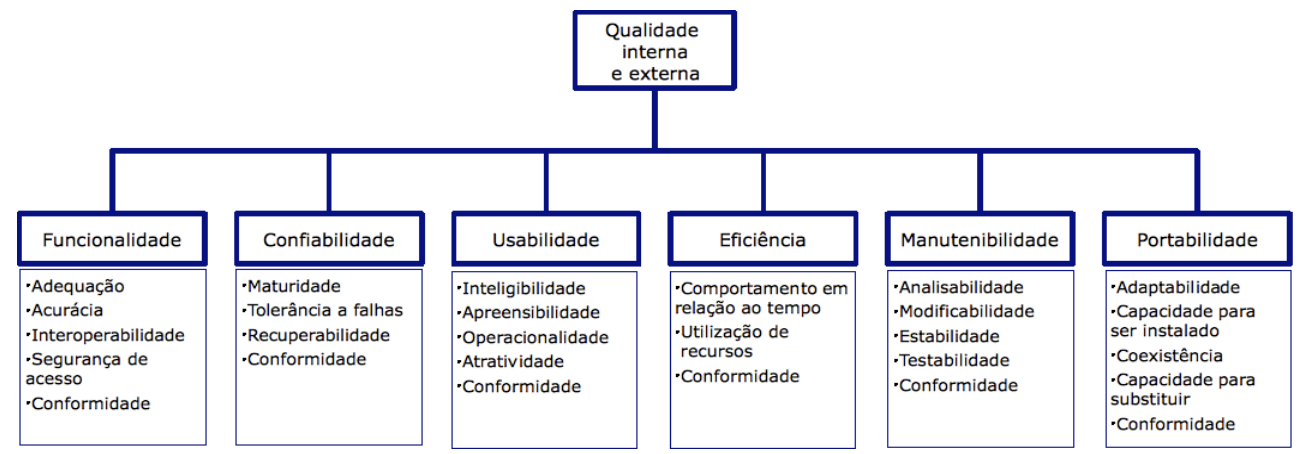

Figura 1 - Características de um software de qualidade segundo a ISO/IEC 9126.

Esses critérios se tornam abrangentes demais ao tentarmos utilizá-los para avaliar softwares educativos, "um software educacional coloca em cena outros elementos, pois a incorporação desses aplicativos só se justifica na medida em que possibilite um avanço qualitativo nos processos de ensino-aprendizagem, concorrendo para uma educação transformadora". (GLADCHEFF et al, 2011).

Para tanto, pesquisamos uma metodologia chamada LORI (Learning Object Review Instrument), desenvolvida pela e-Learning Research and Assessment Network (eLera) como um guia facilitador para avaliação da qualidade de um objeto de aprendizagem (qualquer entidade, digital ou não digital, que possa ser utilizada, reutilizada ou referenciada durante o aprendizado suportado por tecnologias). A avaliação é composta por nove itens, descritos a seguir:

- Qualidade do Conteúdo: Veracidade e apresentação equilibrada das ideias com nível apropriado de detalhes, enfatizando os pontos chaves e ideias significantes.

- Alinhamento do Objetivo da Aprendizagem: Alinhamento entre as metas de aprendizagem, atividades, avaliações e características dos alunos.

- Feedback e Adaptação: Conteúdo adaptável e feedback de acordo com as características específicas do aluno.

- Motivação: Capacidade de motivar o interesse de um público-alvo.

- Design da Apresentação: Referente a informação visual, gráficos, tabelas, animação, entre outros.

- Usabilidade: Facilidade de navegação, previsibilidade da interface do usuário, e qualidade dos recursos de ajuda da interface.

- Acessibilidade: Facilidade do acesso independente de plataforma.

- Reusabilidade: Habilidade para usar em diferentes contextos de aprendizagem e com alunos de diferentes origens.

- Aderência a padrões: Adesão às normas e especificações internacionais.

Da mesma forma que a metodologia de avaliação de qualidade de software da ISO/IEC 9126 era genérica demais para avaliar softwares educacionais, a LORI não 
consegue alcançar as particularidades necessárias para avaliar a qualidade um jogo eletrônico educacional. Para tanto, fez-se necessário pesquisarmos uma metodologia de avaliação de jogos eletrônicos. A GameFlow é uma proposta de avaliação do quão prazeroso é o jogo eletrônico para o jogador. A metodologia propõe a avaliação do jogo eletrônico de acordo com os seguintes critérios:

- Concentração: Jogos devem exigir concentração e permitir que o jogador seja capaz de se concentrar no jogo.

- Desafio: Jogos devem ser suficientemente desafiadores e corresponderem ao nível de habilidade do jogador.

- Habilidade do Jogador: Jogos devem apoiar o desenvolvimento da habilidade do jogador.

- Controle: Os jogadores devem ter sensação de controle sobre suas ações no jogo.

- Objetivos Claros: Jogos devem fornecer metas claras ao jogador.

- Feedback: Os jogadores devem receber feedback adequado em momentos apropriados.

- Imersão: Os jogadores devem ter envolvimento profundo, mas sem esforço no jogo, o envolvimento deve surgir de forma natural.

- Interação Social: Jogos devem apoiar e criar oportunidades de interação social.

\subsection{Proposta De Abordagem Para Avaliação De Jogos Eletrônicos Educacionais}

Nesta seção, propomos uma abordagem para avaliação de jogos eletrônicos baseada na experiência dos autores, tanto no que diz respeito ao que torna um jogo atrativo, quanto ao que torna um jogo educativo, que utiliza alguns critérios da metodologia LORI e alguns critérios da metodologia GameFlow, são eles:

- Qualidade do conteúdo: Veracidade e apresentação equilibrada das ideias com nível apropriado de detalhes, enfatizando os pontos significantes.

- Alinhamento do Objetivo da Aprendizagem: Alinhamento entre as metas de aprendizagem, atividades, avaliações e características dos alunos.

- Motivação: Capacidade de motivar o interesse do jogador.

- Imersão: Capacidade de envolver o jogador profundamente.

- Objetivos Claros: Metas claras do que deve ser realizado.

- Feedback e Adaptação: Elaboração do feedback positivo e negativo do jogo. Conteúdo que se adapta de acordo com a habilidade do jogador.

- Apresentação: Informação visual.

- Interação Social: Dispor meios de interação com outros jogadores.

- Reusabilidade: Capacidade de ser utilizado em diferentes contextos de aprendizagem e com alunos de diferentes idades e interesses.

\subsection{Estudo de caso}

Como exemplo de avaliação de um jogo eletrônico educacional, iremos utilizar os tópicos da abordagem proposta para analisarmos o jogo Stop!. Esse é um jogo bem conhecido e que também pode ser jogado em papel, onde se escolhe vários temas, sorteia-se uma letra e começa-se a preencher os temas onde a inicial de cada palavra 
deve ser a letra sorteada. O jogador que terminar de preencher todos os temas primeiro, grita "Stop!" e os outros jogadores devem parar de preencher.

A versão eletrônica do Stop! pode ser jogada no site centraldejogos.com.br. O jogo é gratuito, precisando somente preencher um cadastro no próprio site e fazer o download do aplicativo da central de jogos, disponível no site também.

Utilizando os critérios de avaliação de jogos eletrônicos educacionais propostos neste trabalho, vamos avaliar o jogo Stop!:

- Qualidade do conteúdo: Possui uma grande quantidade de temas diversos. No caso de temas que mudam conforme o tempo, por exemplo, carros, cada vez que um carro novo é lançado no mercado, demora um pouco para ser incluído no banco de dados e começar a ser pontuado no jogo.

- Alinhamento do Objetivo da Aprendizagem: Dependerá dos planos de ensino de cada professor.

- Motivação: O jogo disponibiliza um ranking dos jogadores com maior pontuação no mês e, além disso, a cada faixa de pontuação, o jogador ganha uma nova graduação, o que o faz querer ganhar mais pontos para atingir o próximo nível.

- Imersão: Como é um jogo que exige velocidade do jogador na hora de pensar na palavra e digitá-la, é um jogo que prende muito a atenção e faz com que o jogador nem perceba a hora passar.

- Objetivos Claros: Tanto no site quanto no próprio programa está explicado o sistema de jogo e de pontuação, de uma forma bem simples.

- Feedback e Adaptação: O jogo utiliza um esquema de cor para mostrar as palavras aceitas e as não aceitas. Após a rodada, se o jogador preencheu um determinado tema com uma palavra igual ao de outro jogador, a palavra aparece na cor cinza e ambos ganham 5 pontos. Se o jogador preencheu um tema com uma palavra diferente de todos os outros jogadores, a palavra aparece na cor laranja e são computados 10 pontos. Se o jogador preencheu um tema em que ninguém mais preencheu com qualquer outra palavra, a palavra aparece na cor azul e são computados 15 pontos. Caso a palavra não tenha sido aceita como válida, ela aparece na cor preta e nenhum ponto é computado.

- Apresentação: O jogo tem gráficos bem simples, como pode ser visto na Figura 2, possui a área da tabela onde são digitadas as palavras referentes aos temas, uma área de chat, onde as pessoas da sala se comunicam, uma área que possui o botão para pedir Stop! e fazer o jogo parar e uma última área onde mostra o nome e a pontuação das pessoas que estão jogando na sala no momento.

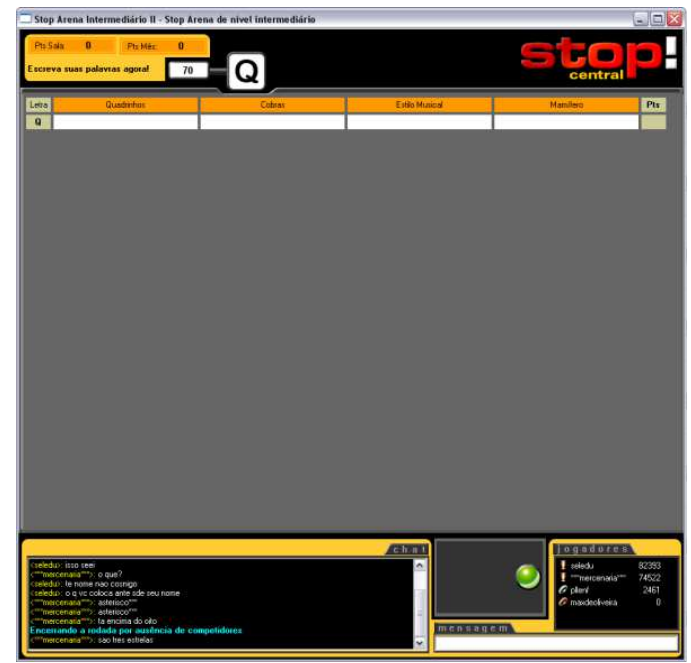

Figura 2 - Demonstração da tela do jogo Stop! 
- Interação Social: O jogo disponibiliza um espaço de chat em todas as salas, onde as pessoas podem se conhecer, fazer brincadeiras ou tirar dúvidas.

- Reusabilidade: O jogo não possui salas com temas específicos, cada sala pode ter qualquer tema de forma aleatória. Porém, existem salas onde as respostas devem ser escritas em inglês.

\section{Considerações Finais}

Este trabalho buscou apresentar, por meio de uma revisão de literatura, argumentos que justificassem o uso de jogos eletrônicos na educação, principalmente no ensino fundamental, onde a tendência é que a parte lúdica do aprendizado comece a ser deixada de lado, como mostrado nas Diretrizes Curriculares Nacionais.

De acordo com o que foi exposto, é possível concluir que os jogos eletrônicos, desde que aplicados sabiamente, como alertam Antunes (2002) e Pietruchinski et al (2001), são ferramentas úteis para uma educação de maior qualidade, seja como complemento prático que se diferencia do paradigma da sala de aula tradicional, como indica Schneider (APUD Santos e Vale, 2006), seja como um meio de desafiar o aluno e forçá-lo a tomar decisões baseadas em seus conhecimentos já adquiridos, como explicam Johnson (2006) e Dohme (2008), ou simplesmente inseri-lo em um ambiente de estudo mais dinâmico, interativo e lúdico, como descrevem Moran (2002) e Santos e Vale (2006).

Também foi possível avaliar que o governo possui programas de auxílios às escolas públicas para equipá-las com laboratórios de informática, tais como ProInfo e o PBLE, capacitando-as a incluir os jogos eletrônicos educacionais em sua programação pedagógica.

Vimos que é necessário ter cautela na aplicação e desenvolvimento dos jogos eletrônicos educacionais, conforme Fontoura (2012) e Tavares (20--), pois quando feitos somente com a intenção de divertimento ou quando aplicados de forma não planejada, podem não surtir efeito positivo e acabarem sendo uma perda de tempo.

Por fim, baseados em uma metodologia de avaliação do quão agradável é um jogo eletrônico (GameFLow) e outra metodologia que examina Objetos de Aprendizagem (LORI), propomos uma abordagem de avaliação de jogos eletrônicos educacionais com o objetivo de auxiliar os professores a refletirem sobre os vários aspectos que envolvem jogos eletrônicos educacionais e escolherem os jogos que melhor se aplicam aos seus planos de ensino.

Tornando o aprendizado motivador e cativante desde as séries iniciais, acreditamos que não haja tantas desistências de alunos no ensino médio, como mostrado na pesquisa Motivos da Evasão Escolar, da FGV-RJ.

\section{Referências}

ANTUNES, Celso. As inteligências múltiplas e seus estímulos. 7ed. Campinas, SP: Papirus, 1998.

Jogos para a estimulação das múltiplas inteligências. 11ed. Petrópolis, RJ :Vozes, 2002.

Blog Educação. Banda larga já chega a $91 \%$ das escolas públicas urbanas do país.

02/2011. Disponível em: <http://www.blogeducacao.org.br/banda-larga-ja-chega-a91-das-escolas-publicas-urbanas-do-pais/>. Acesso em: 28/09/2012. 
Conselho Nacional de Educação. Diretrizes Curriculares Nacionais: Educação Básica. Resolução No 4, de 13 de julho de 2010. Disponível em: <http://portalsme.prefeitura. sp.gov.br/Projetos/BibliPed/Documentos/concurso2012/RESOLU\%C3\%87\%C3\%83 O_CNE_CEB_04_2010.pdf >. Acesso em: 23/11/2012.

DELORS, Jacques. Educação: Um Tesouro a Descobrir. UNESCO, MEC, Cortez Editora, São Paulo, 1999. Disponível em: <http://4pilares.net/text-cont/delorspilares.htm>. Acesso em: 13/06/2012.

Dicionário Interativo da Educação Brasileira. DCNs (Diretrizes Curriculares Nacionais). Disponível em: <http://www.educabrasil.com.br/eb/dic/dicionario.asp? id=96>. Acesso em: 13/06/2012.

DOHME, Vania. Atividades lúdicas na educação: o caminho de tijolos amarelos do aprendizado. 4ed. - Petrópolis, RJ: Vozes, 2008

FONTOURA, Antonio Jr. Jogos educativos e diversão, 2012. Disponível em: $<\mathrm{http}$ ://patolagames.com.br/blog/?p=14>. Acesso em: 13/06/2012.

GLADCHEFF, Ana Paula; Zuffi, Edna Maura; Silva, Menezes Dilma. Um Instrumento para Avaliação da Qualidade de Softwares Educacionais de Matemática para o Ensino Fundamental. VII Workshop de Informática na Escola, Fortaleza-CE, 2011.

JOHNSON, Steven. Videogame faz bem, 2006. Disponível em: <http://veja.abril.com.br/110106/p_066.html>. Acesso em: 13/06/2012.

Ministério da Educação. Programa Banda Larga nas Escolas. Disponível em: $<$ http://portal.mec.gov.br/index.php?Itemid=823\&id=15808\&option=com_content\& view=article $>$. Acesso em: 13/06/2012.

Ministério da Educação. ProInfo. Disponível em: <http://portal.mec.gov.br/index.php? option=com_content $\&$ view=article $\& i d=236 \&$ Itemid=471 $>$. Acesso em: 13/06/2012.

MORAN, José Manuel. Novas tecnologias e mediação pedagógica. 6ed - Papirus, 2002.

Fundação Getúlio Vargas. Motivos da Evasão Escolar. Disponível em: <http://www.fgv.br/cps/tpemotivos/>. Acesso em: 13/06/2012.

Nesbit, J.; Belfer, K.; Leacock, T. Learning Object Review Instrument (LORI): User Manual. Disponível em: <http://www.transplantedgoose.net/gradstudies/educ892/ LORI1.5.pdf >. Acesso em: 13/06/2012.

NEWZOO. Em 2011, brasileiros irão gastar US\$ 2 bilhões em jogos. Disponível em: <http://www.newzoo.com/ENG/1504-Detail.html\&id=94>. Acesso em: 13/06/2012.

PIETRUCHINSKI et al. Os jogos educativos no contexto do SBIE: uma revisão sistemática de Literatura. Anais do XXII SBIE - XVII WIE, 2001. Disponível em: <http://www.br-ie.org/sbie-wie2011/SBIE-Trilha3/93164_1.pdf>. Acesso em: 13/06/2012.

SANTOS, Christiano Lima; VALE, Frederico Santos do. Jogos eletrônicos na educação. 2006. Disponível em: <http://www.programadoresdejogos.com/ trab_academicos/christiano_frederico.pdf $>$. Acesso em: 13/06/2012.

SWEETSER, P.; WYETH. P. GameFlow: A Model for Evaluating Player Enjoyment in Games. The University of Wueensland, St Lucia, Australia. 2005.

TAVARES, Roger. Games na educação: a batalha está começando!, (20--). Disponível em: <http://www.ead.sp.senac.br/newsletter/setembro04/entrevista/ entrevista.htm>. Acesso em: 13/06/2012. 